\title{
No borders in science
}

\author{
Government policies that threaten the international mobility of biomedical students, researchers and physicians \\ stand to imperil scientific progress and innovation at a time when supporting them is paramount.
}

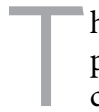

he COVID-19 pandemic has plunged the world into turmoil, with countries issuing lockdown orders and closing their borders in an effort to control their domestic outbreaks. The economic recession triggered as a result is the worst the world has faced in almost a century. In this climate of uncertainty, beyond mounting a science-driven response against the new coronavirus itself, governments need to take bold measures to support the economy and chart the road to recovery.

In the USA this has also involved steps to limit the number of foreign workers, including those in research and healthcare. Thus, last month the US president issued an executive order blocking new work visas under a number of non-immigrant visa programs and extending an earlier order that had already paused new immigrant visas until the end of the year. Although the recent proclamation includes notable exemptions, such as for medical personnel and researchers working on COVID-19, it targets several visa categories widely used for skilled workers, managers and their dependents both in academia and in industry. Additionally, the exclusion of foreign individuals involved specifically in the COVID-19 response may be short-sighted. Science does not advance in a linear or predictable manner, as underscored by the incalculable scientific gains from the rapid COVID-19-focused shifts in the research programs of many labs this year. Shutting the door to researchers whom the administration may consider non-essential for this pandemic may hamper scientific progress essential for the response to this and other crises in the future.

The administration cited the increased US unemployment rate in the months since the pandemic started as the factor driving this new executive order.

However, in recent years, unemployment rates among US workers in science, technology, engineering and math (STEM) have consistently been much lower than the national unemployment rate, indicating an overall shortage in highly specialized STEM workers in the US labor force. Additionally, temporary foreign workers and foreign-born holders of advanced degrees have been reported to boost
US employment. In the absence of specific data showing a sharp reversal of these trends due to the pandemic, it is unclear how curtailing the visa programs that support highly skilled STEM professionals, such as researchers, faculty members and company executives, will benefit the US economy.

Rather, this proclamation follows a series of policies by the current administration that have aimed to restrict the entry of foreign nationals, including scientists and students, into the USA. The most recent example is the guidance issued this month directing foreign students to leave the country, transfer universities or risk deportation, if their universities switch to online-only classes this fall. These actions have alarmed the science and technology communities, who widely consider these policies as a threat to the USA's position as a global leader in these sectors. In addition to filling a gap in the US STEM workforce, global talent helps elevate the scientific enterprise and boosts innovation in the longer term. Insofar as the Nobel Prize is an indicator of the quality of research and level of scientific progress in society, the USA leads other countries in terms of awards in medicine, chemistry and physics. Notably, 35\% of these Nobel Prizes were won by immigrants. Moreover, the impact of immigration on US entrepreneurship is well documented, with immigrants or their children founding or co-founding $24 \%$ of the healthcare companies included in the 2017 Fortune 500 companies. The negative impact that policies seeking to limit foreign-born scientists in the USA would have on day-to-day research enterprise was highlighted in a more anecdotal but visually striking manner on social media, as research group leaders reacted to the most recent executive order by posting pictures of their labs with and without immigrants. In the longer term, such policies could jeopardize the ability of US institutes and companies to attract and retain highly skilled, talented individuals, siphoning research and economic activity to countries with more inviting immigration policies. For example, according to the Canadian Bureau for International Education, Canada has seen a $185 \%$ increase in international students during 2010-2019, and in contrast to the USA, the Canadian government's Global Skills Strategy is focusing on facilitating and accelerating the entry of highly skilled workers into that country.

The consequences of anti-immigration policies are likely to be felt more keenly across the pond, where the UK's decision in 2016 to exit the European Union and the shambolic Brexit strategy that followed are threatening to imperil the country's position as a prime research and education destination. The uncertain access of post-Brexit UK to EU-based collaborative research and medicine networks, including lucrative EU funding schemes such as Horizon Europe, and the prospect of exchanging the EU's freedom-of-movement principles for immigration processes that would by default - be more restrictive, costly and complex, could make the UK a less appealing option for students and scientists from EU countries, to the benefit of other EU member states. It is worth noting that $6 \%$ of students and $18 \%$ of academics in UK higher education currently come from EU countries, not counting the EU citizens working in other STEM professions and industry. The UK scientific community, spearheaded by the Royal Society, has long stressed the need to ensure that Brexit does not harm UK research and innovation. The UK government has been trying to reassure all involved that ensuring adequate research funding and enticing international talent remain priorities. Indeed, UK-EU negotiations for a new trade deal are still ongoing and the hope - for both partners' sake - is that a mutually acceptable agreement will be reached. However, the final Brexit date of 1 January 2021 is fast approaching, and any UK effort to fund research internally and attract highly skilled foreign workers will also depend on the state of its economy. Unfortunately, a recent report from the Organisation for Economic Co-operation and Development warns that the UK faces a deeper COVID-19-related economic recession than that of other countries not only in the EU bloc, but also in the rest of the developed world.

Stakeholders such as academic institutions, business leaders and policymakers need to 
ensure that science and innovation are not stifled by isolationist politics and knee-jerk reactions to the health and economic crisis the world is currently facing. Closing borders may have been essential to control the spread of SARS-CoV-2, but it is equally essential to remember that science speaks an international language and thrives on openness. Supporting the international mobility of scientists and the global exchange of expertise, knowledge and ideas will pave the way not only to addressing the COVID-19 pandemic, but also to fortifying our countries and society against future, unpredictable crises.

Published online: 21 July 2020

https://doi.org/10.1038/s43018-020-0098-3 